\title{
Index of Manuscripts
}

Basel, Universitätsbibliothek, A IX 64519

Basel, Universitätsbibliothek, A IX 64a 519

Cambridge, Corpus Christi College, MS 367 53

Città del Vaticano, Biblioteca Apostolica Vaticana, Ottob. lat. 2541

Città del Vaticano, Biblioteca Apostolica Vaticana, Ottob. lat. 1306522

Città del Vaticano, Biblioteca Apostolica Vaticana, Ottob. lat. 1929522

Città del Vaticano, Biblioteca Apostolica Vaticana, Reg. lat. 1625 (III) 18

Città del Vaticano, Biblioteca Apostolica Vaticana, Ross. 962275

Città del Vaticano, Biblioteca Apostolica Vaticana, Vat. gr. $90 \quad 445$

Città del Vaticano, Biblioteca Apostolica Vaticana, Vat. lat. 1145820

Den Haag, Koninklijke Bibliotheek, 129.G.20 522

Escorial, Real Biblioteca de San Lorenzo, T. II. 8 (gr. 147) 275

Firenze, Biblioteca Medicea Laurenziana, li.10 221

Firenze, Biblioteca Medicea Laurenziana, Conv. Soppr. J.VI.9 41

Firenze, Biblioteca Medicea Laurenziana, Conv. Soppr. 103275

Firenze, Biblioteca Medicea Laurenziana, Plut. $35.30 \quad 36$

Firenze, Biblioteca Medicea Laurenziana, Plut. $85,8275,280$

Hamburg, Staats- und Universitätsbibliothek, Cod. 17 in scrin. 19

Heidelberg, Universitätsbibliothek, Pal. germ. 357390

Heidelberg, Universitätsbibliothek, Pal. germ. $848 \quad 390$

Hildesheim, Dombibliothek, St. God. Nr 1375

Kassel, Universitätsbibliothek, $2^{\circ}$ Ms. theol. 54 361

København, Den Arnamagnæanske Samling, AM $243 \mathrm{~b} \alpha$ fol. 377

København, Det Kongelige Bibliotek, GKS 211 fol. 36

København, Det Kongelige Bibliotek, GKS 2367 4to 370
Leiden, Universiteitsbibliotheek, Voss. Lat. F. 3036

Leiden, Universiteitsbibliotheek, Voss. Lat. Q. 9436

London, British Library, Add. 1198380

London, British Library, Add. 1721017

London, British Library, Add. 1721117

London, British Library, Add. 27169497

London, British Library, Cotton, Nero D. IV 252

London, British Library, Cotton, Vitellius A.xv 53, 361

London, British Library, Harley 978 363, 371

London, British Library, Harley 278217

London, National Archives, C66/308 51

Madrid, Biblioteca Nacional, Ms. Sig. v. 7-17 19

Milano, Ambrosiana, A 45 sup. 152

Milano, Ambrosiana, B 165 sup. (159) 275, 279

Milano, Ambrosiana, E 50 inf. 158

Montpellier, Bibliothèque interuniversitaire, Section Médecine, H 25321

Moskva, Gosudarstvennyj Istoričeskij Muzej, Sinod. Gr. 467154

München, Archäologische Staatssammlung, Bernhard Starks Collectaneen, his. Ver. 18, VIII 19

München, Bayerische Staatsbibliothek, clm 14098361

München, Bayerische Staatsbibliothek, gr. 425 275

Oxford, Bodleian Library, Auct. F. 2. 8

Oxford, Bodleian Library, Digby 23

Oxford, Bodleian Library, Huntington 600

Paris, Bibliothèque nationale de France, fr. 19183522

Paris, Bibliothèque nationale de France, gr. 510 282

Paris, Bibliothèque nationale de France, gr. 515 158

Paris, Bibliothèque nationale de France, gr. 923156

Paris, Bibliothèque nationale de France, gr. 1810275

Paris, Bibliothèque nationale de France, lat. 1030718

¿ Open Access. (C 2020 Philipp Roelli, published by De Gruyter.

(c) BY This work is licensed under the Creative Commons Attribution 4.0 Public License.

https://doi.org/10.1515/9783110684384-013 
Paris, Bibliothèque nationale de France, lat. 1031864

Paris, Bibliothèque nationale de France, Rothschild $2855 \quad 522$

Reims, Bibliothèque municipale, $875 \quad 22,215$

Reykjavík, Safn Árna Magnússonar, GKS 2365 40 155, 362

Salamanca, Biblioteca de la Universidad, ms. 2109523

Salzburg, Stiftsbibliothek St. Peter, a. VII. 5 248

Sélestat, Bibliothèque humaniste, MS 8841

Sinai, St Catherine’s Monastery, gr. 399158

Soissons, Bibliothèque Municipale, 204522

St. Gallen, Stiftsbibliothek, Cod. Sang. 18951

St. Gallen, Stiftsbibliothek, Cod. Sang. 231 66

St. Gallen, Stiftsbibliothek, Cod. Sang. 359 579

St. Gallen, Stiftsbibliothek, Cod. Sang. 569 80
St. Gallen, Stiftsbibliothek, Cod. Sang. 857 143,420

St. Emmeram, fragmentary manuscript 22 Stockholm, Kungliga biblioteket, Holm perg 6 fol. 366

Stuttgart, Württembergische Landesbibliothek, H.B. XIII, poet. germ. I 390

Trier, Bibliothek des Priesterseminars, Ms 100 21

Trier, Stadtbibliothek, Ms. 1353/132 264

Uppsala, Universitetsbiblioteket, DG 4-7 360 Uppsala, Universitetsbiblioteket, DG 11370 Valenciennes, Bibliothèque municipale, 411 80

Venezia, Biblioteca Marciana, gr. Z 191275

Wien, Österreichische Nationalbibliothek, Cod. 10736

Wien, Österreichische Nationalbibliothek, Phil. gr. 7275

Wien, Österreichische Nationalbibliothek, Phil. gr. 123456

Zürich, Zentralbibliothek, 2.103143 